\title{
The APS Transfer Line from Linac to Injector Synchrotron.
}

\author{
R. K. Koul and E. Crosbie \\ Argonne National Laboratory
}

This note describes the low-energy-transfer-line designed for the APS. The low energy transfer line constitutes two transport lines. One of these lines runs from linac to the positron accumulator ring, also called "PAR", and is $23.7138 \mathrm{~m}$ long. The second part of the low energy transport line runs from the "PAR" to the injector synchrotron and is about $30.919 \mathrm{~m}$ long. The above length includes two quadrupoles, a bend magnet and a septum magnet in the injector synchrotron (see fig. 1 and table 2).

The positron bunches of emittance $\epsilon_{N}=1.1 \mathrm{~mm}-m \mathrm{mad}$ arriving at the end of the linac at $450 \mathrm{MeV}$ have twiss parameters as given by Nassiri ${ }^{1}$

$$
\alpha_{x}=1.6808, \beta_{x}=7.2161, \alpha_{y}=-1.7586, \beta_{y}=6.6888
$$

The transfer line (see also Yoon and Crosbie ${ }^{2}$ ) from linac to "PAR" is made up of ten quadrupoles and one bending magnet B4 (see fig.1). The bending magnet bends the beam by 0.2 radians towards the septum magnet in the "PAR". The five quadrupoles in the region between the bend magnet and the septum magnet in the "PAR" give a phase shift of $2 \pi$ radians, in order to get dispersion free bunch at the end of the septum magnet. The twiss parameters at the end of the linac given above are matched with the twiss parameters and the dispersion functions at the end of the septum magnet, in the "PAR" lattice structure. These parameters at the end of the "PAR" septum are given by

$$
\alpha_{x}=-0.94910, \beta_{x}=2.1261, \alpha_{y}=-0.02429, \beta_{y}=8.2401, \eta_{x}=0.0, \eta_{x}^{\prime}=0.0
$$

The matching procedure was carried out using computer code "COMFORT". It should be mentioned that the $2.9 \mathrm{~m}$ of distance between the last quadrupole and the septum magnet in the "PAR" is more or less forced on us because of the considerations of the 


\section{DISCLAIMER}

Portions of this document may be illegible in electronic image products. Images are produced from the best available original document. 
available space in that region. The layout of this region of the transfer line is shown in fig. 1. Details of the magnet dimensions and their strengths are given in table 1. The order of the magnets is the order in which they appear in the transfer line as one traverses from the linac to "PAR". The $\beta$ functions in the horizontal and the vertical plane along with the dispersion function, $\eta$, in the horizontal plane are shown in the fig. 2. The maximum $\beta_{y}$ is approximately $20 \mathrm{~m}$ and occurs at the quadrupole before the bend magnet. The maximum value of the $\beta_{x}$ is about $16 \mathrm{~m}$.

In addition to the above elements, the linac to "PAR" part of the low energy transfer line contains eight steering magnets and seven beam position monitors. Of the eight steering magnets four are for steering in the horizontal plane and the remaining four are to be used for steering in the vertical plane. Similarly, out of the seven beam position monitors three are to be used for diagnostics in the horizontal plane and the remaining four for diagnostics in the vertical plane. The relative positions of these steering magnets are also given in fig. 1. The calculations for the strength and the dimension of these steering magnets was carried out using a computer code locally developed for this purpose. However the code was tested for the calculation of twiss parameters against the "COMFORT" run. Two sample plots for the particle trajectory along the horizantle direction for a given kick, obtained by the above computer code are given in the fig. 4 and fig. 5 .

The second part of the low energy transport line carries the positron bunches from the "PAR" septum to the injector synchrotron. Again the energy of the positron bunches is about $450 \mathrm{MeV}$. This section is made up of two bend magnets (B1, B2), and eleven quadrupoles joining the "PAR" septum magnet "B3" on the one end and the injector synchrotron septum magnet on the other end. The bend magnet B2 bends the bunch, coming from the "PAR" septum magnet (bend angle of -0.2 radians) through an angle of 0.2 radians. The section between the bend magnet B2 and the septum magnet B3 is the same as the section between the bend magnet B4 and the septum magnet B3. It produces dispersion free beam in the region between B2 and B1. The next section between bending magnet B2 and the bending magnet B1 has four quadrupoles which can be used as tuning quadrupoles for tuning on to four twiss parameters in the vertical and horizontal direction. The bend magnet $\mathrm{B} 1$ bends the beam at an angle of -0.1859 radians approximately towards the injector synchrotron septum. There are two quadrupoles in 
the section between the bend magnet B1 and the injector synchrotron septum, which are arranged such that the bunches entering the injector synchrotron are dispersion free at the end of the dipole magnet B (see Table 2). The detailed layout can be seen in fig. 1, and the relative positions the dimensions and the strengths of the magnets are given in table 2. The maximum value of the $\beta$ function from $\mathrm{B} 2$ to the injector synchrotron septum is about $26 \mathrm{~m}$. In designing the transfer line from the "PAR" to the injector synchrotron, some part of the injector synchrotron is included. The twiss parameters given by the injector synchrotron lattice at the beginning of the drift $\mathrm{O} 1$ (see Table 2.) are matched with the twiss parameters given at the beginning of the "PAR" septum magnet given above (sign of the $\alpha$ function must be reversed), through the transfèr line. Again, the computer code "COMFORT" was used for matching purposes. The twiss parameters at the position O1 are given bellow. The sign of the $\alpha$ function corresponds to the motion from "PAR" to the injector synchrotron.

$$
\alpha_{x}=0.4620, \beta_{x}=2.1724, \alpha_{y}=-2.5084, \beta_{y}=15.6557
$$

The detailed form of the $\beta_{x}, \beta_{y}$ and the $\eta_{x}$ is given in the fig. 3 . In addition to the above components this part of the transfer line contains six steering magnets and seven beam position monitors. Out of the six steering magnets, three are used for steering in the horizontal direction and the remaining three in the vertical direction. Similarly, of the seven beam position monitors four are to be used for monitoring the horizontal position and the remaining three for monitoring the vertical position. The maximum $B \ell=0.012$ T.m for these steering magnets. These calculations were carried out using, as mentioned above, a locally developed code. The details of their positions and other parameters are given in the table 2 .

\section{DISCLAIMER}

This report was prepared as an account of work sponsored by an agency of the United States Government. Neither the United States Government nor any agency thereof, nor any of their employees, makes any warranty, express or implied, or assumes any legal liability or responsibility for the accuracy, completeness, or usefulness of any information, apparatus, product, or process disclosed, or represents that its use would not infringe privately owned rights. Reference herein to any specific commercial product, process, or service by trade name, trademark, manufacturer, or otherwise does not necessarily constitute or imply its endorsement, recommendation, or favoring by the United States Government or any agency thereof. The views and opinions of authors expressed herein do not necessarily state or reflect those of the United States Government or any agency thereof. 


\section{References}

1. Alli Nassiri, Private communication.

2. M. Yoon and E. Crosbie, APS note LS-119 (1988). 
Table 1: LTOP PARAMETERS

(150 MeV. $\mathrm{B} \rho=1.503 \mathrm{~T}$-meter: -Positive $K_{1}$ means horizontal defocussing.)

Input Twiss Parameters: $\alpha_{z}=1.6808, \beta_{z}=7.2161, \alpha_{y}=-1.7586: \beta_{y}=6.6888$

Output Twiss Parameters: $\alpha_{z}=-0.09 \cdot 19, \beta_{x}=2.1261_{1} \alpha_{z}=-0.02 \cdot 13: \beta_{y}=8.2 \cdot 101$

\begin{tabular}{|c|c|c|c|c|}
\hline Element & Length & $\begin{array}{l}\theta \text { or Magnet Strength } \\
K_{1}=B^{\prime} / B \rho[m]^{-2}: \rho[m]\end{array}$ & Theta1 & Theta2 \\
\hline DRIFT:OI & 1.81 & & & \\
\hline $\begin{array}{l}\text { Steeringy } \\
\text { DRIFT:O1 }\end{array}$ & $\begin{array}{c}0.05 \\
0.1\end{array}$ & 0.18 & & \\
\hline QUAD:QI & 0.3 & 1.32161191 & & \\
\hline DRIFT: 02 & 2.36 & & & \\
\hline QUAD:Q2 & 0.3 & -0.791189118 & & \\
\hline DRIFT:O3 & 0.1 & & & \\
\hline $\begin{array}{l}\text { Steering } \\
\text { DRIFT:O3 }\end{array}$ & $\begin{array}{l}0.05 \\
2.65\end{array}$ & 0.18 & & \\
\hline QUAD:Q3 & 0.3 & -1.22176903 & & \\
\hline DRIFT:OA & 2.01 & & & \\
\hline $\begin{array}{c}\text { BPMY } \\
\text { DRIFT:O1 }\end{array}$ & 0.1 & & . & \\
\hline QUAD:Q4 & 0.3 & 2.22022831 & & \\
\hline DRIFT:OJ & 0.1 & & - & \\
\hline $\begin{array}{l}\text { Steering } \\
\text { DRIFT:Oj }\end{array}$ & $\begin{array}{c}0.05 \\
1.78697\end{array}$ & 0.18 & & \\
\hline $\begin{array}{c}\text { BPM } \\
\text { DRIFT:O5 }\end{array}$ & 0.1 & & & \\
\hline QUAD:QJ & 0.3 & -2.90560107 & & \\
\hline DRIFT:06 & 0.1 & & . & \\
\hline $\begin{array}{l}\text { Steering } \\
\text { DRIFT:06 }\end{array}$ & $\begin{array}{l}0.05 \\
0.63\end{array}$ & 0.18 & & \\
\hline SEEND:BY & 0.1 & 0.2 & 0.1 & 0.1 \\
\hline DRIFT:OT' & 0.30 & & & \\
\hline $\begin{array}{c}\text { BPM, } \\
\text { DRIFT:OT }\end{array}$ & 0.1 & & & \\
\hline QUAD:Q11 & 0.3 & 1.13661613 & & \\
\hline DRIFT:09 & 0.1 & & & \\
\hline $\begin{array}{l}\text { Steering } \\
\text { DRIFT:099 }\end{array}$ & $\begin{array}{l}0.05 \\
0.75\end{array}$ & 0.18 & & \\
\hline $\begin{array}{c}\text { BPMA } \\
\text { DRIFT:O9 }\end{array}$ & 0.1 & & & \\
\hline QUAD:Q15 & 0.3 & -1.87910321 & & \\
\hline DRIFT:09 & 0.1 & & & \\
\hline $\begin{array}{l}\text { Steering } \\
\text { DRIFT:Og }\end{array}$ & $\begin{array}{l}0.05 \\
0.75\end{array}$ & 0.18 & & \\
\hline $\begin{array}{c}\text { BPM, } \\
\text { DRIFT:O9 }\end{array}$ & 0.1 & & & \\
\hline QUAD:Q16 & 0.3 & 1.2311 & & \\
\hline DRIFT:Og & 0.1 & & & \\
\hline $\begin{array}{l}\text { Steering, } \\
\text { DRIFT:O99 }\end{array}$ & $\begin{array}{l}0.05 \\
0.75\end{array}$ & 0.18 & & \\
\hline $\begin{array}{c}\text { BPA, } \\
\text { DRIFT:O9 }\end{array}$ & 0.1 & & & \\
\hline QUAD:Q17 & 0.3 & -3.6 .1756051 & & \\
\hline DRIFT:09 & 0.1 & & & \\
\hline $\begin{array}{l}\text { Steering } \\
\text { DRIFT:09 }\end{array}$ & $\begin{array}{l}0.05 \\
0.35\end{array}$ & 0.13 & & \\
\hline QUAD:Q18 & 0.3 & 0.518257169 & & \\
\hline DRJFT:O8 & 0.3 & & & \\
\hline $\begin{array}{c}\text { BPM } \\
\text { DRIFT:OB }\end{array}$ & 2.606796672 & & & \\
\hline$S B C \mathcal{N D}: \mathrm{B} 3$ & 0.1 & -0.2 & -0.0 & -0.2 \\
\hline
\end{tabular}


Table 2: PTOB PARABETERS

(150 $\mathrm{MeV} . \mathrm{B} \rho=1.303 \mathrm{~T}$-meter, -Positive $K_{1}$ means horizontal defocussing.)

Input Twiss Parameters: $\alpha_{z}=1.6808, \beta_{x}=7.2161, \alpha_{y}=-1.7386, \beta_{y}=6.6888$

Ontput Twiss Parameters: $\alpha_{x}=-0.09 \cdot 19: \beta_{z}=2.1261, \alpha_{y}=-0.0213, \beta_{y}=8.2 \cdot 101$

\begin{tabular}{|c|c|c|c|c|}
\hline Element & Length & $\begin{array}{c}\theta \text { or Mlagnet Strength } \\
K_{1}=B l / B \rho[m]^{-2, p[m]}\end{array}$ & Thetal & Theta2 \\
\hline$S B E N^{\prime} D: B 3$ & 0.4 & -0.2 & 0.0 & -0.2 \\
\hline DRIFT:014 & $2.9067966 \pi 2$ & & & \\
\hline QUAD:Q13 & 0.3 & 0.318257169 & & \\
\hline DRIFT:013 & 0.9 & & & \\
\hline$B P A=$ & & & & \\
\hline DRIFT:O13 & 0.1 & & & \\
\hline QUAD:Q12 & 0.3 & -3.64756051 & & \\
\hline DRIFT:012 & 0.1 & & & \\
\hline Steering & 0.05 & 0.21 & & \\
\hline DRIFT:012 & 0.73 & & & \\
\hline$B P M_{y}$ & & & & \\
\hline DRIFT:012 & 0.1 & & & \\
\hline QUAD:Q11 & 0.3 & 40.23 .11 & & \\
\hline DRIET:011 & 0.1 & & - & \\
\hline Steering & 0.05 & 0.07 & & \\
\hline DRIFT:O11 & 0.75 & - & & \\
\hline$B P \lambda I_{*}$ & & & & \\
\hline DRIFT:011 & 0.1 & & & \\
\hline QUAD:Q10 & 0.3 & -4.87910321 & & \\
\hline$D R I F T: 010$ & 0.1 & & 1. & \\
\hline Steering & 0.05 & 0.153 & & \\
\hline$D R I F T: 010$ & 0.75 & & & \\
\hline$B P_{5}$ & & & & \\
\hline DRIFT:010 & 0.1 & & & \\
\hline QUAD:Q9 & 0.3 & 1.13661613 & & \\
\hline DRIFT:O9 & 0.1 & & & \\
\hline Steering & 0.05 & 0.15 & & \\
\hline DRIFT:09 & 0.75 & & & \\
\hline$S B E X \cdot D: \mathrm{B} 2$ & 0.4 & 0.2 & 0.1 & 0.1 \\
\hline DRIFT:3E & 0.50 & & & \\
\hline$B P M_{*}$ & & & & \\
\hline DRIFT:8E & 0.1 & & & \\
\hline QUAD:Q3 & 0.3 & -2.524011 .18 & & \\
\hline DRIFT:BD & 0.60 & & & \\
\hline QUAD:Q7 & 0.3 & 2.53513652 & & \\
\hline DRIFT:8C & $0.372796-15$ & & & \\
\hline Steering & 0.05 & 0.18 & & \\
\hline DRIFT:\& & 0.1 & & & \\
\hline QUAD:Q6 & 0.3 & -2.51912868 & & \\
\hline DRIFT:ஃB & 0.3 & & & \\
\hline$B P M_{y}$ & & & & \\
\hline DRIFT:ßB & 0.10 & & & \\
\hline QUAD:Q5 & 0.3 & $2.7450,5532$ & & \\
\hline DRIFT:\$A & 0.1 & & & \\
\hline Steering & 0.05 & 0.13 & : & \\
\hline DRIFT:SA & 0.15 & & & \\
\hline SEEND:B1 & 0.1 & -0.13586022 & -.09293011 & -.09293011 \\
\hline DRIFT:O7 & $1.739 \cdot 150176$ & & & \\
\hline$B P M=$ & & & & \\
\hline DRIFT:O7 & 0.1 & & & \\
\hline QUAD:Q1 & 0.30 & -1.3278606 .4 & & \\
\hline DRIFT:06 & 0.9 & & & \\
\hline QUAD:Q3 & 0.30 & 0.82701161 & & \\
\hline \multirow[t]{2}{*}{ DRIFT:OS } & 0.9 & & & \\
\hline & (Inside Booster) & (Inside Booster) & & \\
\hline SEE.VD:SEP & 0.8 & 0.26751 & 0.13377 & 0.13377 \\
\hline DRIFT:01 & 1.55 & & & \\
\hline QUAD:Q2 & 0.30 & 0.633272 & & \\
\hline DRIFT:O3 & 0.311 .5 & & & \\
\hline SEEND:B & 3.077 & -0.09239973 & 0.01619989 & 0.01619989 \\
\hline$D R I F T: 02$ & 0.3115 & & & \\
\hline QUAD:Q1 & 0.50 & -0.710 .565 & & \\
\hline DRIFT:OI & 1.1 & & & \\
\hline
\end{tabular}




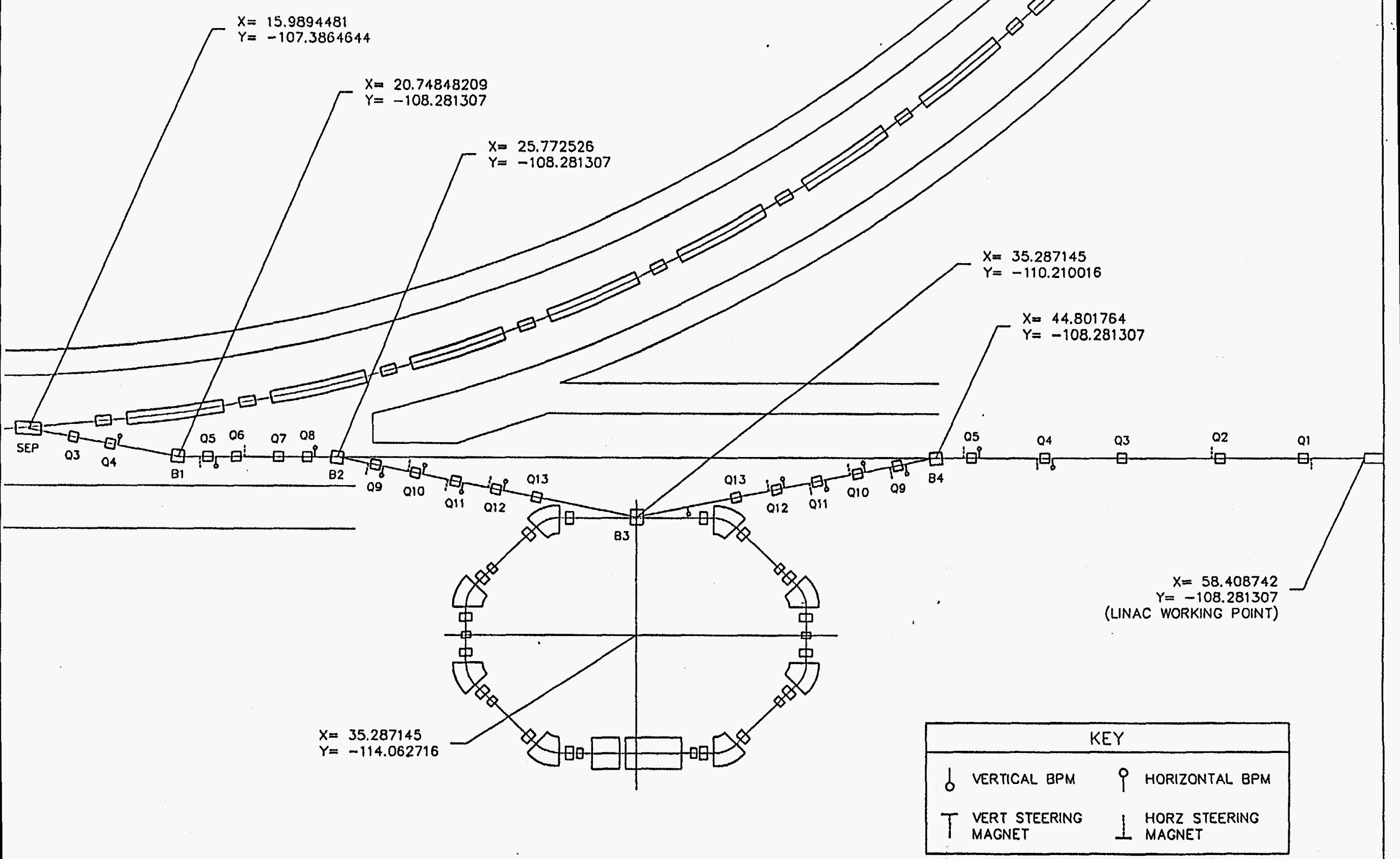

FIGURE 1. LOW ENERGY TRANSPORT LINE 


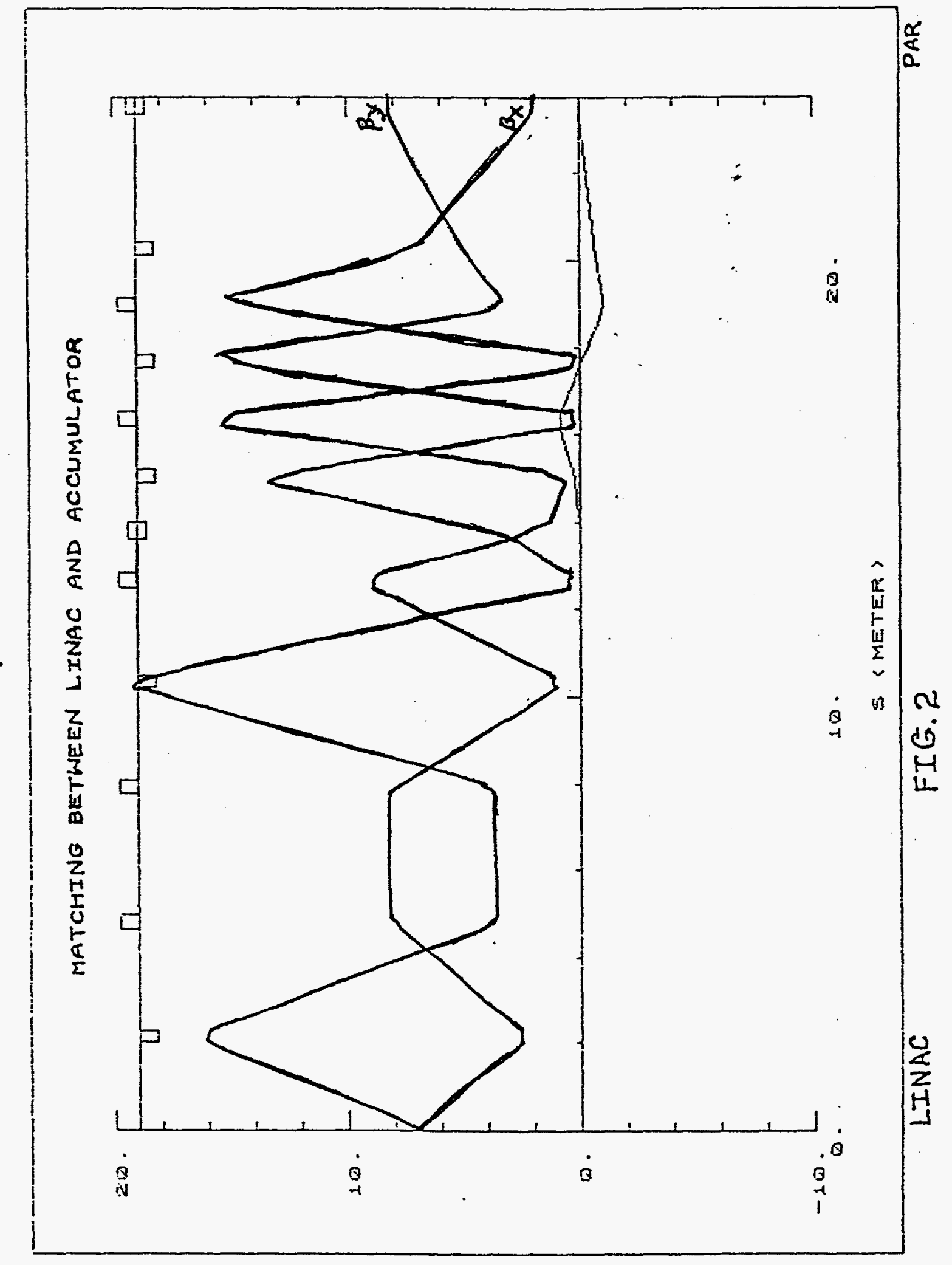




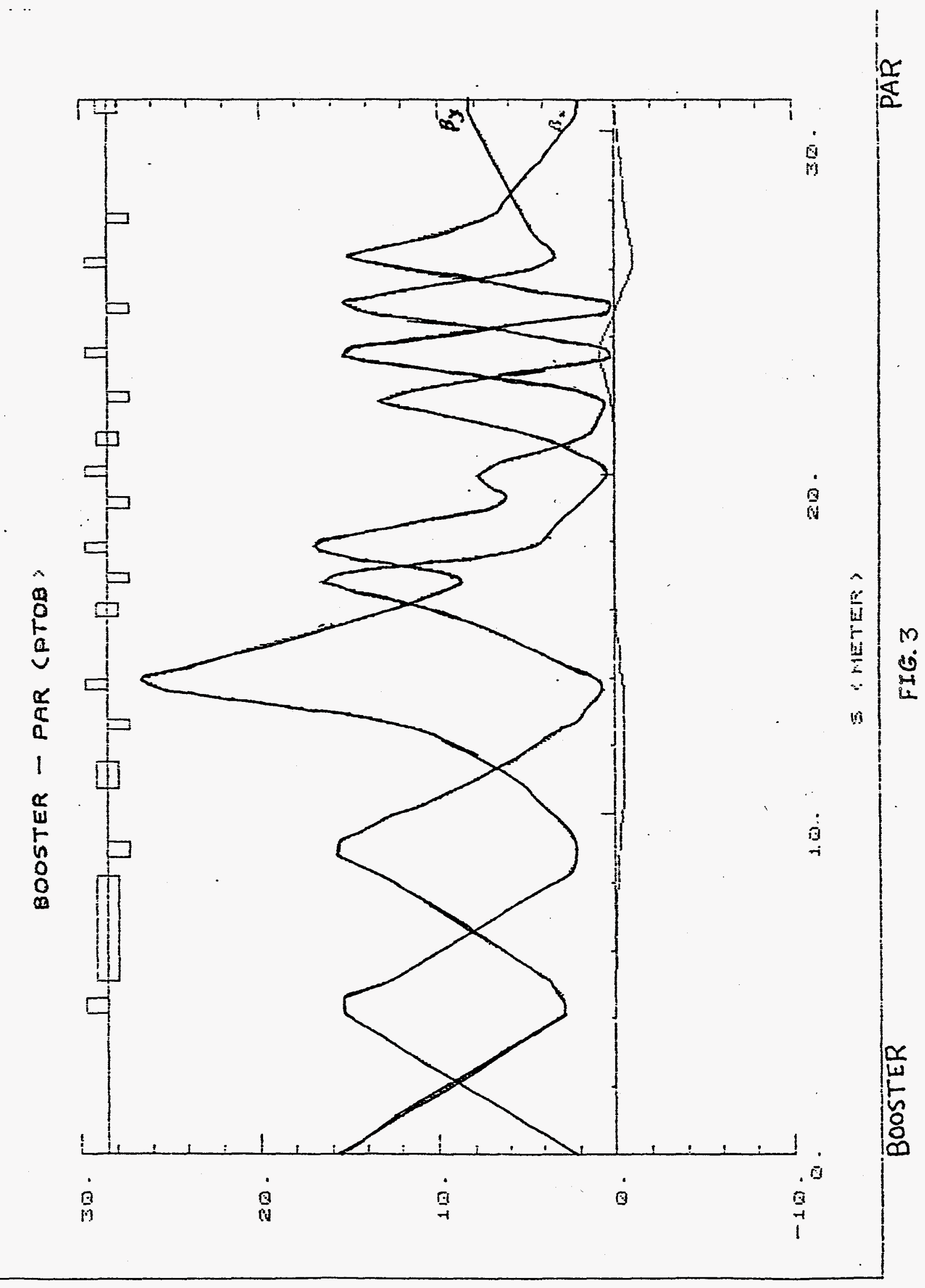




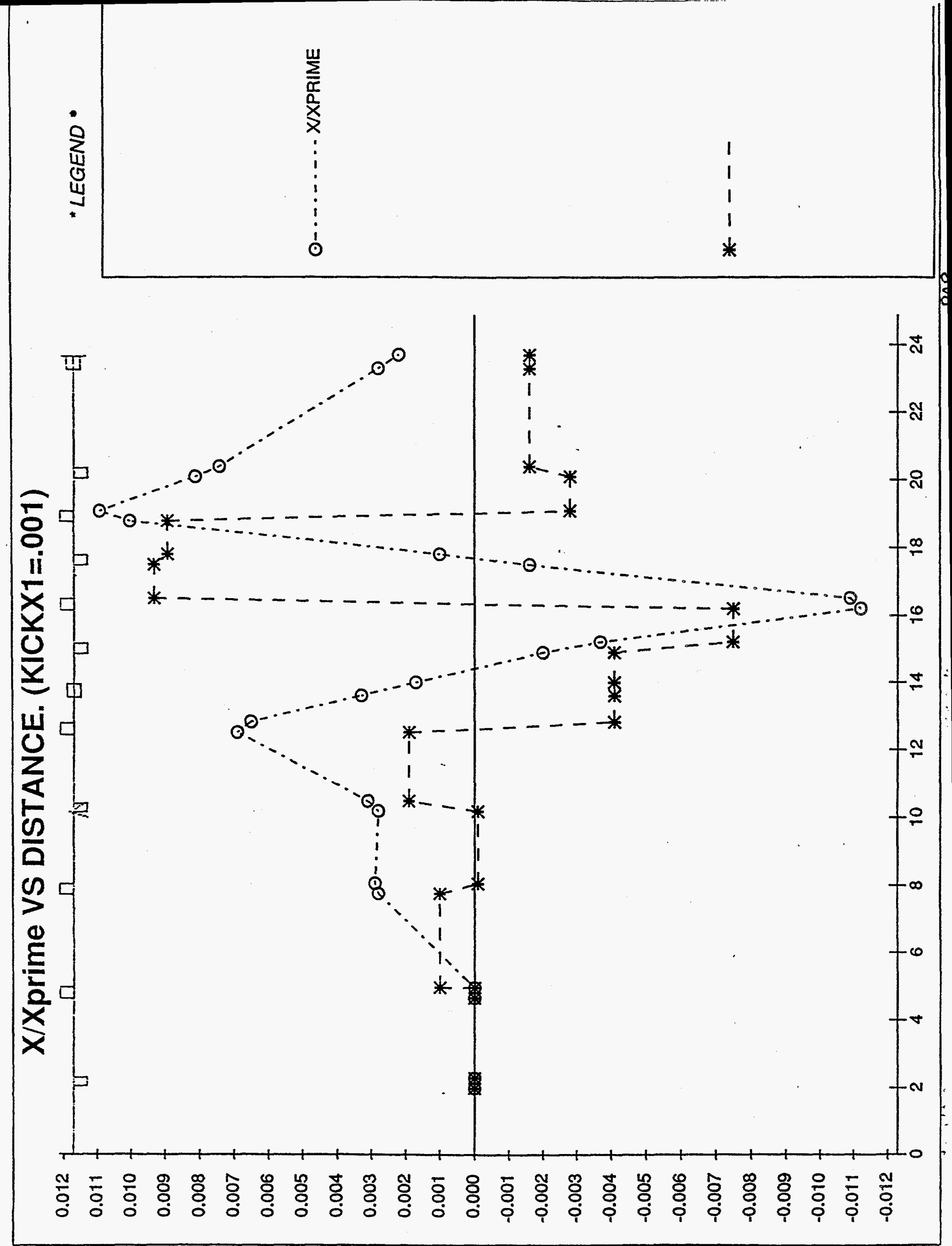




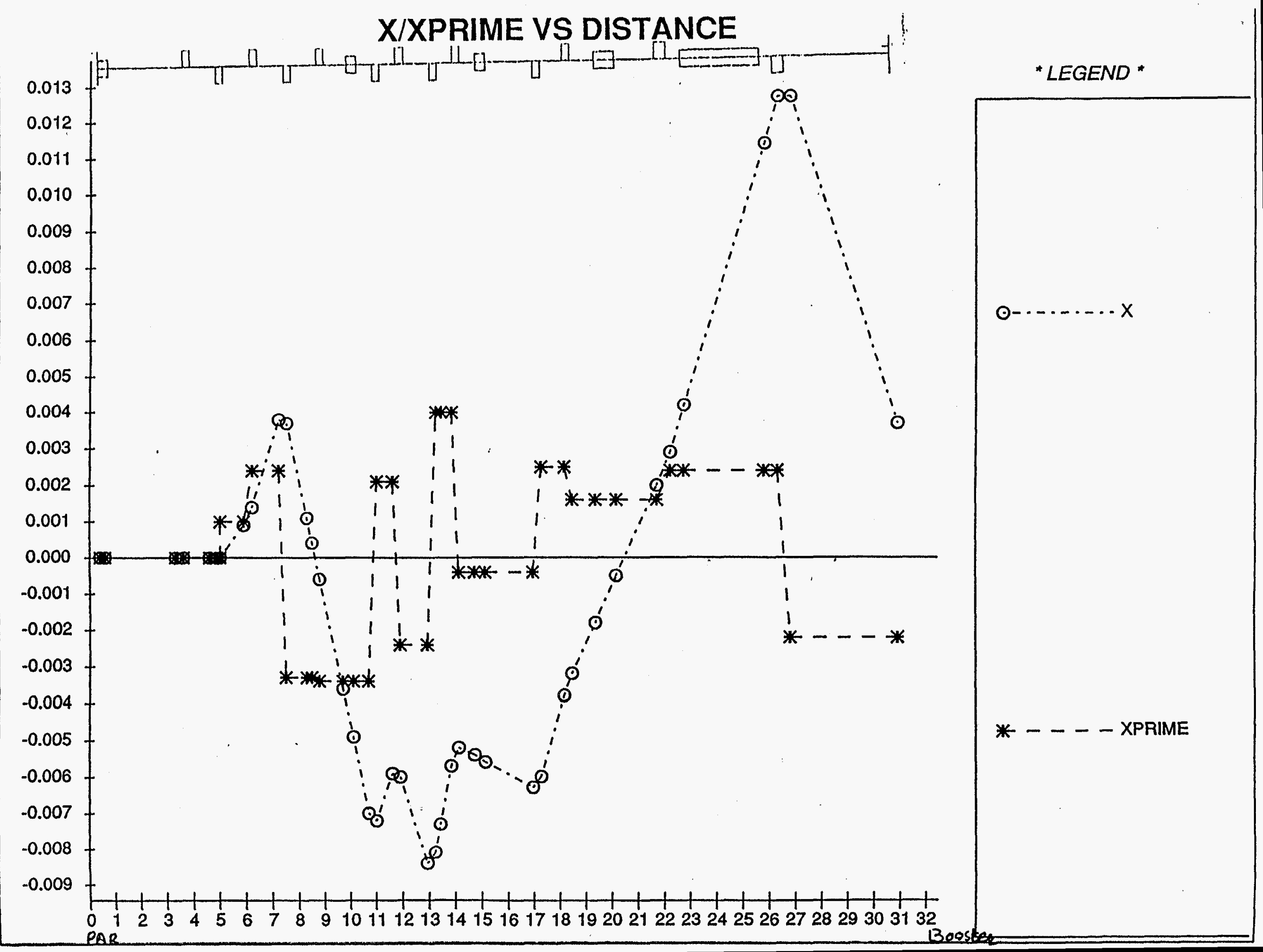

